\section{Urinary Catheter Indications in the United States: Results from a National Survey of Acute Care Hospitals}

\author{
M. Todd Greene, $\mathrm{PhD}, \mathrm{MPH} ;{ }^{1,2, a}$ \\ Hiroko Kiyoshi-Teo, PhD, RN; ; ${ }^{3, a}$ Heidi Reichert, MA; $;^{1,2}$ \\ Sarah Krein, PhD, RN; ${ }^{1,2,4}$ Sanjay Saint, MD, $\mathrm{MPH}^{1,2,4}$
}

In a survey of acute care hospitals across the United States, we found that many hospitals use indwelling urinary catheters for reasons that are not medically necessary (eg, urinary incontinence without outlet obstruction and patient/family requests). Our findings highlight an opportunity to reduce unnecessary catheter use through promoting awareness of appropriate use.

Infect Control Hosp Epidemiol 2014;35(S3):S96-\$98

Indwelling urinary catheters are commonly used medical devices. An estimated $25 \%$ of hospitalized patients have catheters placed during their hospital stay.' Guidelines from the Centers for Disease Control and Prevention's Healthcare Infection Control Practices Advisory Committee (HICPAC) recommend limiting the use of indwelling catheters and provide examples of both appropriate and inappropriate indications for catheter use. ${ }^{2}$ Between $20 \%$ and $50 \%$ of catheters placed in acute care settings may not be medically necessary. ${ }^{1,3-5} \mathrm{Re}-$ ducing inappropriate use of catheters has the potential to prevent catheter-associated urinary tract infection (CAUTI) and other noninfectious consequences of catheter use, such as pain, trauma, and mobility restriction. ${ }^{6}$

Although previous studies have investigated catheter appropriateness in single-site settings, we are unaware of any other studies that have examined indications for catheter placement as used by hospitals across the United States. Thus, we sought to determine how often various indications for catheter use were reported among a nationally representative sample of acute care hospitals.

\section{METHODS}

In March 2009, survey questionnaires were distributed to a random sample of US hospitals. Details regarding the sample and survey instrument have been described previously. ${ }^{7,8}$ In brief, the survey instrument was mailed to lead infection preventionists at 588 nonfederal acute care hospitals with at least 50 patient beds and an intensive care unit (ICU). The survey instrument included questions about general facility and infection control program characteristics as well as practices related to preventing CAUTI and other device-associated infections. Respondents were also asked to select all of the indications for catheter placement used at their facility from a list of indications informed by the HICPAC guidelines. ${ }^{2}$ Descriptive statistics were generated to determine frequencies of indication use. $\chi^{2}$ and $t$ tests were used to assess potential associations between hospital characteristics and the use of the various catheter indications.

\section{RESULTS}

A total of 406 hospitals responded to our survey, representing a response rate of $69 \%$. The average bed size was 226 , and the mean full-time equivalent infection preventionist was 1.8 . A total of $70 \%$ of the respondents were registered nurses, and $64 \%$ were certified in infection control.

Table 1 illustrates the use of the various catheter indications. A majority of respondents indicated that their facility used catheter indications deemed appropriate by CAUTI prevention guidelines. ${ }^{2}$ Despite this, we found that many hospitals were also using several indications deemed inappropriate by the same guidelines. ${ }^{2}$ Of note, nearly half used urinary incontinence without outlet obstruction (42.4\%) and more than onethird used patient/family request (34.2\%) as indications for catheter placement. We found that hospitals that were affiliated with a medical school (32\% vs $47 \% ; P=.01)$ and facilities with a greater number of full-time-equivalent infection preventionists (2.0 vs $1.6 ; P=.04$ ) reported less frequent use of the urinary incontinence without outlet obstruction indication. Conversely, this indication was reported more frequently among hospitals reporting bed or unit closures due to nurse staffing issues ( $52 \%$ vs $40 \% ; P=.05$ ). Hospitals that utilized hospitalists more frequently reported using the patient/family request indication $(37 \%$ vs $24 \% ; P=.02)$.

\section{DISCUSSION}

Although the majority of hospitals responding to our survey reported using indications deemed appropriate by HICPAC recommendations, ${ }^{2}$ several inappropriate indications were used frequently. This finding complements results from a recent study of hospitals participating in a national CAUTI prevention initiative funded by the Agency for Health Research and Quality," which showed that between 30\% and $40 \%$ of catheters outside the ICU may not be appropriately indicated. ${ }^{10}$ The reported frequent use of urinary incontinence without outlet obstruction in the current study is consistent with prior work showing urinary incontinence as the major cause of initial unjustified catheter placement. ${ }^{4}$ Urinary incontinence is a prevalent condition, ranging from $14 \%$ in men to $51 \%$ in women, " and may be a symptom of complex underlying conditions. As such, it is possible that selection of this indication was motivated by particular patient characteristics. Additionally, we found that use of this indication was more frequent in hospitals reporting staffing issues and in hospitals with less support and fewer resources for infection control. The relatively high use of patient/family requests in 
TABLE 1. Urinary Catheter Indications $(N=406)$

\begin{tabular}{|c|c|c|}
\hline Indication & No. $(\%)$ & $\begin{array}{l}\text { Appropriate per } \\
\text { HICPAC guidelines }\end{array}$ \\
\hline Output monitoring in critically ill & $390(96.1)$ & Yes \\
\hline Prolonged surgical procedures & $376(92.6)$ & Yes \\
\hline Acute urinary retention or bladder outlet obstruction & $366(90.1)$ & Yes \\
\hline Urinary incontinence without obstruction in patients with pressure sores & $328(80.8)$ & Yes \\
\hline Urinary incontinence without obstruction & $172(42.4)$ & No \\
\hline Patient/family request & $139(34.2)$ & No \\
\hline Nursing workload & $36(8.9)$ & No \\
\hline Other & $46(11.3)$ & $\ldots$ \\
\hline
\end{tabular}

Note. HICPAC, Healthcare Infection Control Practices Advisory Committee, Centers for Disease Control and Prevention.

a Includes hospice or end-of-life care, surgery/anesthesia, acute and chronic urinary retention, trauma, burn, fracture, immobility, being in intensive care unit, and physician order.

our study parallels recent findings from qualitative assessments identifying patient/family requests for catheterization as one of the barriers to reducing catheter use. ${ }^{12}$

Our study has several limitations. First, as our response rate was not $100 \%$, our results are prone to nonresponse bias. Second, the use of catheter indications at each hospital was based on the response of one infection preventionist. Furthermore, the use of indications was not mutually exclusive, and we were not able to quantify which indications were being used most frequently. Finally, we did not collect patient-level data with which to quantify actual indications used or control for patient-level characteristics.

Limitations notwithstanding, our study provides insights into which indications are being selected for catheter placement in US hospitals. A majority of hospitals reported using catheters for appropriate reasons that are aligned with HICPAC guideline recommendations. ${ }^{2}$ However, we found that several inappropriate indications were also being reportedly used quite regularly. Of note, our findings suggest that specific patient and hospital characteristics may be driving the use of inappropriate indications, such as urinary incontinence without obstruction and patient/family requests. Identifying and implementing strategies that would help bolster infection control programs may help increase awareness of catheter appropriateness and reduce inappropriate catheter use. Additionally, in an era of increasingly patient-centric care, healthcare providers have an increased responsibility for informing patients and family members of the potential consequences of catheters when requests for catheterization are made in the absence of concurrent, appropriate indications.

\section{ACKNOWLEDGMENTS}

Financial support. This project was supported by the Blue Cross Blue Shield of Michigan Foundation (to S.S.) and the National Institute of Nursing Research (5 R01 NR010700 to S.S. and S.K.). This project was also partially supported by a contract from the Agency for Healthcare Research and Quality (HHSA2902010000251/HHSA29032001T).

Potential conflicts of interest. S.S. reports that he has received numerous honoraria and speaking fees from academic medical centers, hospitals, grouppurchasing organizations (eg, Premier and VHA), specialty societies, statebased hospital associations, and nonprofit foundations (eg, the Michigan Health and Hospital Association and the Institute for Healthcare Improvement) for lectures about catheter-associated urinary tract infection, implementing change, and leadership. All authors report receiving support for involvement in the "On the CUSP: Stop CAUTI" initiative funded by the Agency for Healthcare Research and Quality. All authors submitted the ICMJE Form for Disclosure of Potential Conflicts of Interest, and the conflicts that the editors consider relevant to this article are disclosed here.

Affiliations: 1. Department of Internal Medicine, University of Michigan Medical School, Ann Arbor, Michigan; 2. Veterans Affairs/University of Michigan Patient Safety Enhancement Program, Ann Arbor, Michigan; 3. School of Nursing, Oregon Health Sciences University, Portland, Oregon; 4. Veterans Affairs Ann Arbor Healthcare System and the Hospital Outcomes Program of Excellence, Department of Veterans Affairs, Ann Arbor, Michigan.

Address correspondence to $\mathrm{M}$. Todd Greene, $\mathrm{PhD}, \mathrm{MPH}$, University of Michigan Medical School, 2800 Plymouth Road, Building 16, Ann Arbor, MI 48109-2800 (mtgreene@med.umich.edu).

a These authors contributed equally to this article.

Received April 14, 2014; accepted April 16, 2014; electronically published September 15, 2014.

(C) 2014 by The Society for Healthcare Epidemiology of America. All rights reserved. 0899-823X/2014/35S3-0014\$15.00. DOI: $10.1086 / 677823$

\section{REFERENCES}

1. Gokula RR, Hickner JA, Smith MA. Inappropriate use of urinary catheters in elderly patients at a midwestern community teaching hospital. Am J Infect Control 2004;32(4):196-199.

2. Gould CV, Umscheid CA, Agarwal RK, Kuntz G, Pegues DA; Healthcare Infection Control Practices Advisory Committee. Guideline for prevention of catheter-associated urinary tract infections 2009. Infect Control Hosp Epidemiol 2010;31(4):319-326.

3. Gardam MA, Amihod B, Orenstein P, Consolacion N, Miller MA. Overutilization of indwelling urinary catheters and the development of nosocomial urinary tract infections. Clin Perform Qual Health Care 1998;6(3):99-102.

4. Jain P, Parada JP, David A, Smith LG. Overuse of the indwelling urinary tract catheter in hospitalized medical patients. Arch Intern Med 1995;155(13):1425-1429.

5. Munasinghe RL, Yazdani H, Siddique M, Hafeez W. Appropriateness of use of indwelling urinary catheters in patients ad- 
mitted to the medical service. Infect Control Hosp Epidemiol 2001;22(10):647-649.

6. Hollingsworth JM, Rogers MA, Krein SL, et al. Determining the noninfectious complications of indwelling urethral catheters: a systematic review and meta-analysis. Ann Intern Med 2013; 159(6):401-410.

7. Saint S, Kowalski CP, Kaufman SR, et al. Preventing hospitalacquired urinary tract infection in the United States: a national study. Clin Infect Dis 2008;46(2):243-250.

8. Krein SL, Hofer TP, Kowalski CP, et al. Use of central venous catheter-related bloodstream infection prevention practices by US hospitals. Mayo Clin Proc 2007;82(6):672-678.

9. Fakih MG, George C, Edson BS, Goeschel CA, Saint S. Implementing a national program to reduce catheter-associated uri- nary tract infection: a quality improvement collaboration of state hospital associations, academic medical centers, professional societies, and governmental agencies. Infect Control Hosp Epidemiol 2013;34(10):1048-1054.

10. Greene MT, Fakih MG, Fowler K, et al. Regional variation in urinary catheter use and catheter-associated urinary tract infection: results from a national collaborative. Infect Control Hosp Epidemiol 2014;35(suppl 3):S99-S106 (in this issue).

11. Markland AD, Richter HE, Fwu CW, Eggers P, Kusek JW. Prevalence and trends of urinary incontinence in adults in the United States, 2001 to 2008. J Urol 2011;186(2):589-593.

12. Krein SL, Kowalski CP, Harrod M, Forman J, Saint S. Barriers to reducing urinary catheter use: a qualitative assessment of a statewide initiative. JAMA Intern Med 2013:1-6. 